\title{
Medicinal Plants as a Drug Alternative Source for the Antigout Therapy in Morocco
}

\author{
Nour Elhouda Daoudi (D), Mohamed Bouhrim (D), Hayat Ouassou (D), \\ and Mohamed Bnouham iD \\ Laboratory of Bioresources Biotechnology Ethnopharmacology and Health, Department of Biology, Faculty of Sciences,
University Mohamed It $I^{\text {, Oujda, Morocco }}$ \\ Correspondence should be addressed to Mohamed Bnouham; mbnouham@yahoo.fr
}

Received 14 July 2020; Revised 4 November 2020; Accepted 10 November 2020; Published 23 November 2020

Academic Editor: Abdel Halim Salem

Copyright (C) 2020 Nour Elhouda Daoudi et al. This is an open access article distributed under the Creative Commons Attribution License, which permits unrestricted use, distribution, and reproduction in any medium, provided the original work is properly cited.

\begin{abstract}
Background. The gout is a metabolic disease that is associated with a high level of uric acid in the blood. This disease is treated with some medications that aim to reduce serum urate levels. However, the use of various medicines leads to the appearance of some side effects, hence the importance of using other treatments based on natural resources. Objective. This study presents some medical treatments, their side effects, and some plants that are used for gout management in Morocco in the aim to valorize them. Methods. We have been consulting various English publications in PubMed, Web of Science, and ScienceDirect published between 1991 and 2019 using the following keywords "drugs," "gout," "Morocco," "medicinal plants," "in vitro," and "in vivo" terms. Then, we have classified the medicines, according to their action mechanisms, and we have cited some species that were reported in Moroccan pharmacopeia as antigout. Results. Three methods of the gout medical management were cited in this work: xanthine oxidase inhibitors, uric acid excretion enhancer, and uricase recombinant. However, it was found that these treatments had various side effects. We have described 23 species, and some of them showed experimentally an antigout effect by blocking the "xanthine oxidase" enzyme. These plants belong to 11 families. Lamiaceae represents the most dominant family with six species followed by Asteraceae with two species. Colchicine isolated from Colchicum autumnale is the most known compound for its efficiency towards gout. Conclusion. This work summarized different treatments particularly medicinal plants that are used in Morocco to treat gout disease by blocking uric acid secretion. However, several studies are needed to valorize these antigout natural sources.
\end{abstract}

\section{Introduction}

Gout is a chronic disorder, which is known also as "a disease of kings." Sir Alfred Baring Garrod discovered it in 1848 [1]. This disease is characterized by the deposition of urate crystal in several tissues [2]. It affects many joints, particularly the first metatarsophalangeal joint of the foot. Additionally, it attacks the arms, knees, and ankles [3]. Mostly, this disease is associated with many risk factors as hyperuricemia, genetic factors, metabolism syndrome, dietary factors, alcohol consumption, osteoarthritis, kidney failure, diuretic, and some medication uses [4].

The most frequent inflammatory arthritis in the world is gout. It is characterized by prevalence higher than $1 \%$ in the occidental countries, especially in Europe and North America [1]. Actually, recent works suggest that men have a higher prevalence and incidence of gout than women $[1,4]$. Indeed, it is necessary to take this disease seriously because it is associated with various health complications as cardiovascular risk, hypertension, chronic kidney disorder, obesity, and metabolic syndrome [5-7].

The main cause of hyperuricemia is the unbalance between the production and excretion rate of uric acid. Purines principally degraded by a hepatic enzyme named xanthine oxidase are involved in the appearance of hyperuricemia. A high-purine diet that leads to purine metabolism raise, excessive alcohol consumption, and tumor lysis syndrome associated with the alteration of a large number of cells, 
contributing to the increased uric acid production. Indeed, a reduction in excretion and rising reabsorption of uric acid causes hyperuricemia. Furthermore, uric acid transporters are required in uric acid renal handling which consists of tubular reabsorption/secretion and glomerular filtration. In fact, reabsorption-related proteins include generally glucose transporter 9 (GLUT9), organic anion transporter 4 (OAT4), and urate anion transporter 1 (URAT1). However, secretion-related transporters include OAT1, OAT3, multidrug resistance protein 4 (MRP4/ABCC4), and breast cancer resistance protein (BCRP/ABCG2) [8] (Figure 1).

Generally, gout is treated with some medications to lower the level of the serum urate by the inhibition of the xanthine oxidase in the liver. Among those treatments, we have febuxostat and allopurinol [9]. Colchicine extracted by Colchicum autumnale is another kind of gout therapy [10]. Unfortunately, these drugs have various side effects. For example, allopurinol causes nephrolithiasis, renal toxicity, liver necrosis, and allergic reactions [11]. For these, people seek better alternatives based on the use of medicinal plants because of their availability, easy accessibility, and people believe that natural products are not harmful [12]. Morocco is characterized by flora diversity, and it contains 4200 species in which 800 are considered therapeutic herbs [13]. The medicinal plants of this country have been used traditionally to treat several complications as gout. In fact, several plants were reported in pharmacopeia as antigout products, and most of them have shown experimentally this activity. Although, these plants remain underexploited and require other studies in order to confirm this effect and to identify different molecules responsible for this beneficial effect. Therefore, in this review, we have summarized information about medical treatment and plants that are used for gout management in Morocco with the aim to valorize the Moroccan bioresources. For this reason, we have been consulting various English publications in PubMed, Web of Science, and ScienceDirect databases, published between 1991 and 2019.

\section{Medical Treatment}

The principle of gout management is based on reducing and maintaining the serum urate at the normal value $(<6.0 \mathrm{mg} / \mathrm{d})$ [9]. Generally, there are three methods employed to reach this objective. The first one allows inhibiting the xanthine oxidase enzyme (allopurinol and febuxostat) and then blocking the production of uric acid and their precursor. The second one is intended to enhance uric acid excretion. The third strategy is based on the administration of recombinant uricases to convert uric acid to allantoin (Table 1) $[9,20]$.

\section{Plants Used Traditionally to Treat Gout in Morocco}

Medicinal plants have a prominent place in Moroccan phytotherapy as they contain several bioconstituents and antioxidants that are responsible for their beneficial effects. These plants and their compounds can be used as alternative or complementary medicines against gout pathology. Table 2 classifies medicinal plants that are used traditionally in Morocco to manage gout disease.

Figure 2 shows the different families of the plants that had an antigout effect. In fact, the Lamiaceae family is the most dominant with six species, followed by Asteraceae with two herbs and the other families, which contain only one species for each one.

\section{Discussion}

Gout is a metabolic disease, characterized by burning, acute arthritis, and pain, which are the consequences of monosodium urate deposition into the joints $[49,50]$.

The release of interleukin-1 $\beta$ (IL- $1 \beta$ ), which is a cytokine, plays a key role in the initiation of the gout disease. Actually, the crystals lead to the activation of monocyte and then releasing caspase- 1 , which induces the IL- $1 \beta$ secretion [51]. The blocking of this cytokine represents an effective treatment of acute and chronic gout. Among IL- $1 \beta$ inhibitors that are used, there are anakinra, canakinumab, rilonacept, and pralnacasan [52-55].

Diet plays also a role in the decrease of the uric acid level. In fact, beer, red meat, and sugar-sweetened beverages are responsible for the appearance of gout [20]. In the other hand, it was reported that some food consumption such as "cheery juice" (Prunus cerasus; Rosaceae), food that contains a high amount of vitamin C; coffee; and dairy products could maintain the uric acid's rate at normal values and then the management of gout $[56,57]$.

Experimentally, there are several animal models of gout which are mainly monosodium urate crystal depositioninduced acute inflammation, potassium oxonate-induced hyperuricemia, and carrageenan-induced inflammation. In fact, uric acid is considered as a weak organic acid, and it is able to be ionized to monosodium urate crystal at $\mathrm{pH}=7.4$ and at $37^{\circ} \mathrm{C}$. Consequently, uric acid and urate crystals could deposit into the tissues, particularly joints and kidney, contributing to tissue damage [8]. The formation of monosodium urate crystals lead to the activation of macrophages that play a role in the secretion of inflammatory cytokines as IL-1 $\beta$. These mediators initiate with complement of (activated at crystals surfaces) a neutrophilic influx that is pathophysiologic feature of acute-gout. During the infiltration, crystals activate neutrophils, which contribute to the production of additional proinflammatory mediators such as arachidonic acid products (prostaglandine E2 and leukotriene B4). Monosodium urate crystals could persist into the joint fluid between attacks, which suggest that the inflammatory potential of monosodium urate crystals may be modulated by synovial fluid elements [58]. Potassium oxonate is a selective competitive inhibitor of uricase that play a key role in the conversion of uric acid to allantoin. Then, it induced hyperuricemia in rodents by blocking the effect of liver uricases [59]. Indeed, it was reported that potassium oxanate-induced hyperuricemic in rats developed a high level of renal proteins (URAT1 and GLUT9) and decreased the level of OTA1. However, the involved mechanisms are not clear yet [60]. The carrageenan-induced paw edema is another experiment model of gout that 


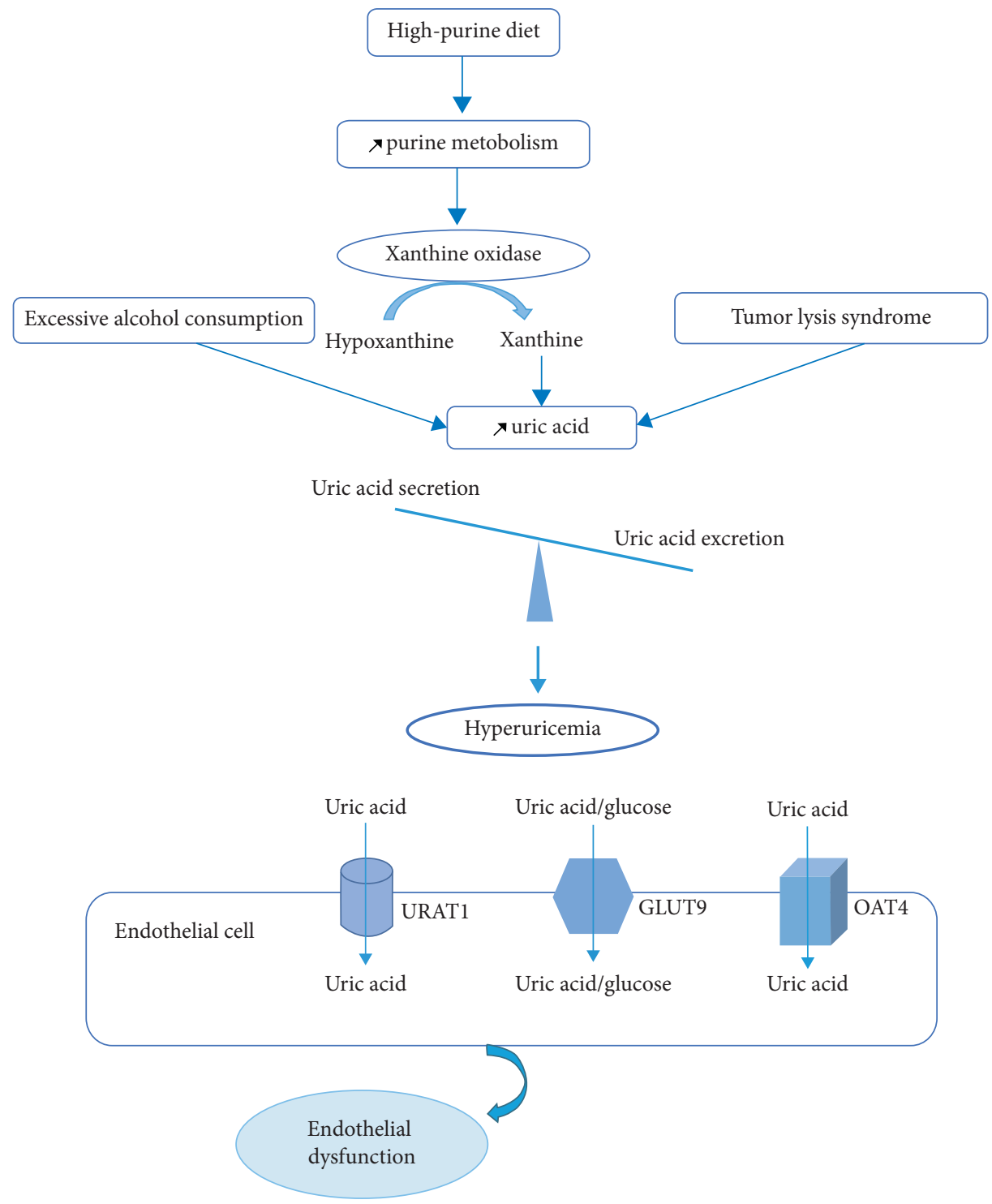

FIGURE 1: Mechanisms underlying hyperuricemia.

involves several inflammatory mediators such as TNF- $\alpha$ and IL-1 $\beta$. In fact, TNF- $\alpha$ triggers IL- $\beta \beta$ release and cytokineinduced neutrophil chemoattractant 1 which play a key role in the stimulation of the prostaglandins synthesis by cyclooxygenase-2. Furthermore, TNF- $\alpha$ activates iNOS responsible for $\mathrm{NO}$ synthesis, and then the responses of neutrophils increases to inflammatory stimuli [61].

Several agents are implicated in the treatment of gout disease as cyclooxygenase inhibitors, steroids, anti-inflammatory drugs, xanthine oxidase inhibitors, uricosuric, and uricases agents. Although these drugs are efficient, they are associated with various side effects such as digestives disorders, hepatotoxicity, renal dysfunction, hypersensitivity reaction, and skin allergy [62]. Actually, people search for alternatives that are characterized by their availability, fewer undesirable effects, and lower costs. These alternatives are based on medicinal plants.

In this review, we are citing some natural sources that are used traditionally in Morocco to treat gout disease. The table classifies 23 species, their scientific names, families, the traditionally used parts, traditional use method, experimental used part, extraction methods, and the experimental study towards gout, and we are reporting the toxic plants. In fact, the cited plants had shown experimentally an antigout effect by blocking and inhibiting "xanthine oxidase" which is the enzyme that catalyzes xanthine and hypoxanthine to uric acid. Xanthine oxidase inhibitors play an essential role to reduce uric acid levels, oxidative stress, and inflammation in the kidney and are able to prevent glomerular hypertension, afferent arteriolar, and ischemic renal histologic changes [63]. Besides, plants contain bioactive compounds that can enter into the active site of xanthine oxidase, producing a complex xanthine oxidase-bioactive compound through hydrophobic forces, related with surrounding xanthine oxidase amino acid and occupied the active site, thus preventing the entrance of substrate and inhibiting uric acid synthesis [64]. The histogram presented in this review shows the different families to which the studied plants belong. The 
TABLE 1: The gout treatment drugs and their side effects.

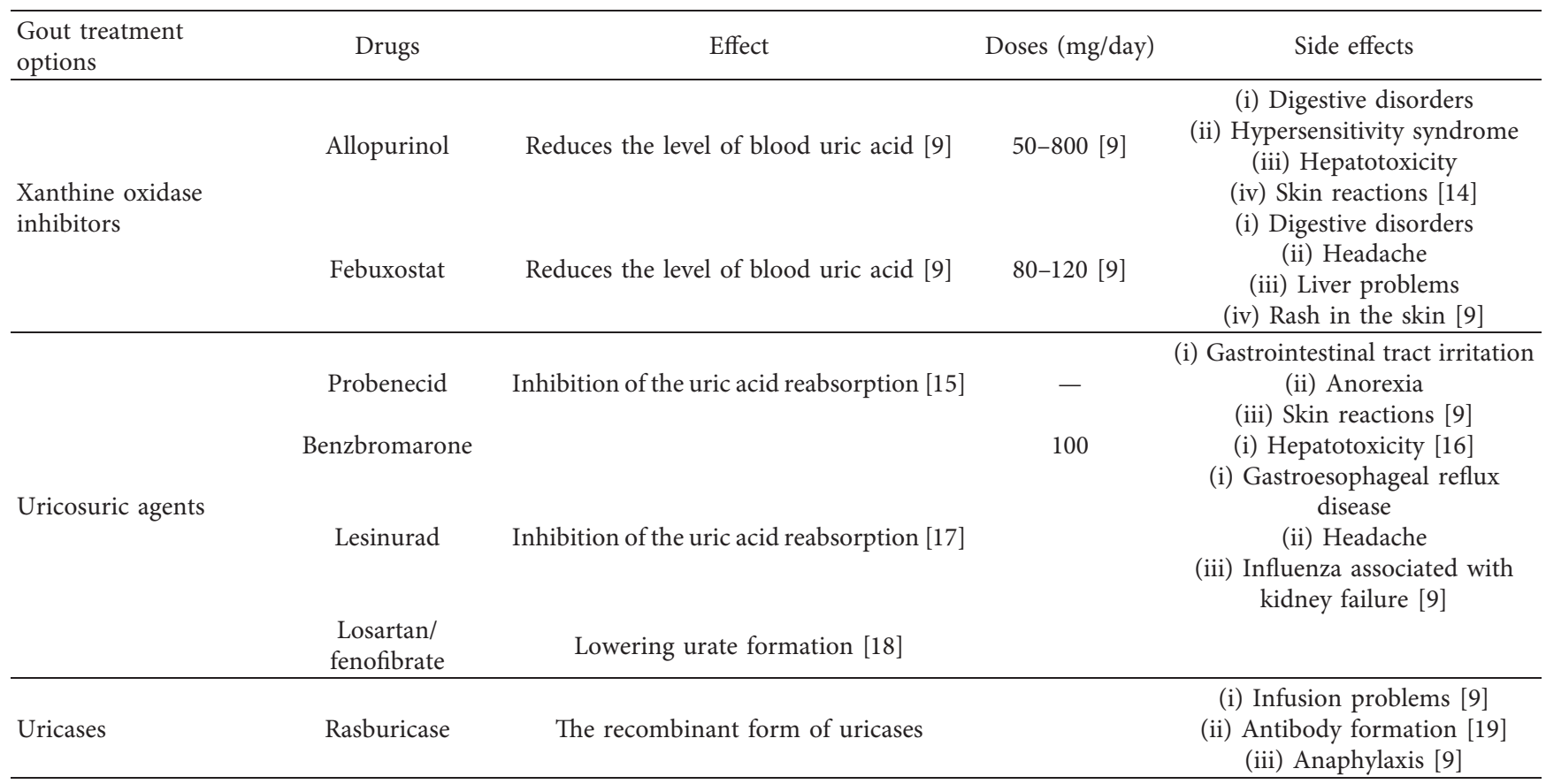

Lamiaceae family is the most dominant family with six species. Recently, it was reported that the phenolic compounds isolated from the Lamiaceae herbs had anti-inflammatory and antioxidant actions $[65,66]$. Besides, species belonging to this family had shown a potent xanthine oxidase inhibition, and it was recommended to use them to prevent and treat gout disease [67].

Capparis spinosa $L$. is the plant that has shown the highest inhibitory effect on xanthine oxidase activity than the other plants. The chloroform and ethyl acetate aerial part extract have shown a lower value of $\mathrm{IC}_{50}(0.023$ and $0.09 \mathrm{mg} /$ $\mathrm{mL}$, respectively), followed by chloroform extract of root $(0.32 \mathrm{mg} / \mathrm{mL})$, which means that these extracts are characterized by a potential activity on xanthine oxidase effect [27]. However, in vitro assay corresponds to in vitro enzymatic reactions of the enzyme xanthine oxidase. It allows to investigate directly the effect of plants on the xanthine oxidase inhibition activity. These studies do not require the use of a high number of animals in tests. However, it does not take into account the bioavailability of the principles active agents. Therefore, in vitro analysis is not enough and must confirmed by in vivo assays; using the different experimental animal models of gout.

Several phytochemical studies have reported the presence of alkaloids, terpenoids, saponins, phenolic compounds, carotenoids, and tocopherols in C. spinosa L. [68] that may act as xanthine oxidase inhibitors [64]. Fruits and leaves parts of this plant have shown the presence of phenolic and flavonoid compounds, particularly caffeic acid, catechin, chlorogenic acid, coumarin, ferulic acid, kaempferol, luteolin, quercetin, resveratrol, rutin, syringic acid, and vanillic acid which possesses an important xanthine oxidase inhibition $[64,69-72]$. Furthermore, the roots are characterized by the presence of capparispine, cadabicine $26-\mathrm{O}-\beta-\mathrm{D}$-glucoside, capparispine $26-\mathrm{O}-\beta$-D-glucoside, stachydrine, and 3-hydroxy-7-methoxy-2-methyl-4H-1,4-benzoxazine-4-carbaldehyde [73].

Colchicine is a natural drug that is isolated from Colchicum autumnale [10]. For almost 250 years, it was used as an anti-inflammatory agent [74]. Now, this alkaloid is used to manage gout disease, neurologic disability, familial Mediterranean fever, liver cirrhosis, amyloidosis, scleroderma, and Behcet's disease [75]. However, it can be toxic as it may cause gastrointestinal disorder and respiratory paralysis. For this reason, it is recommended to administer it according to therapeutic guidelines [76].

Gout has an important relationship with diabetes. Actually, the prevalence of gout in type 1 and 2 diabetes was, respectively, $1.9 \%$ and $10.12 \%$ [77]. Besides, many studies showed that people suffering from gout have a higher risk to develop type 2 diabetes [78]. Hyperuricaemia leads kidney failure, which is the consequence of crystal deposition in the renal tract. Moreover, type 2 diabetes can further aggravate this consequence [79]. 


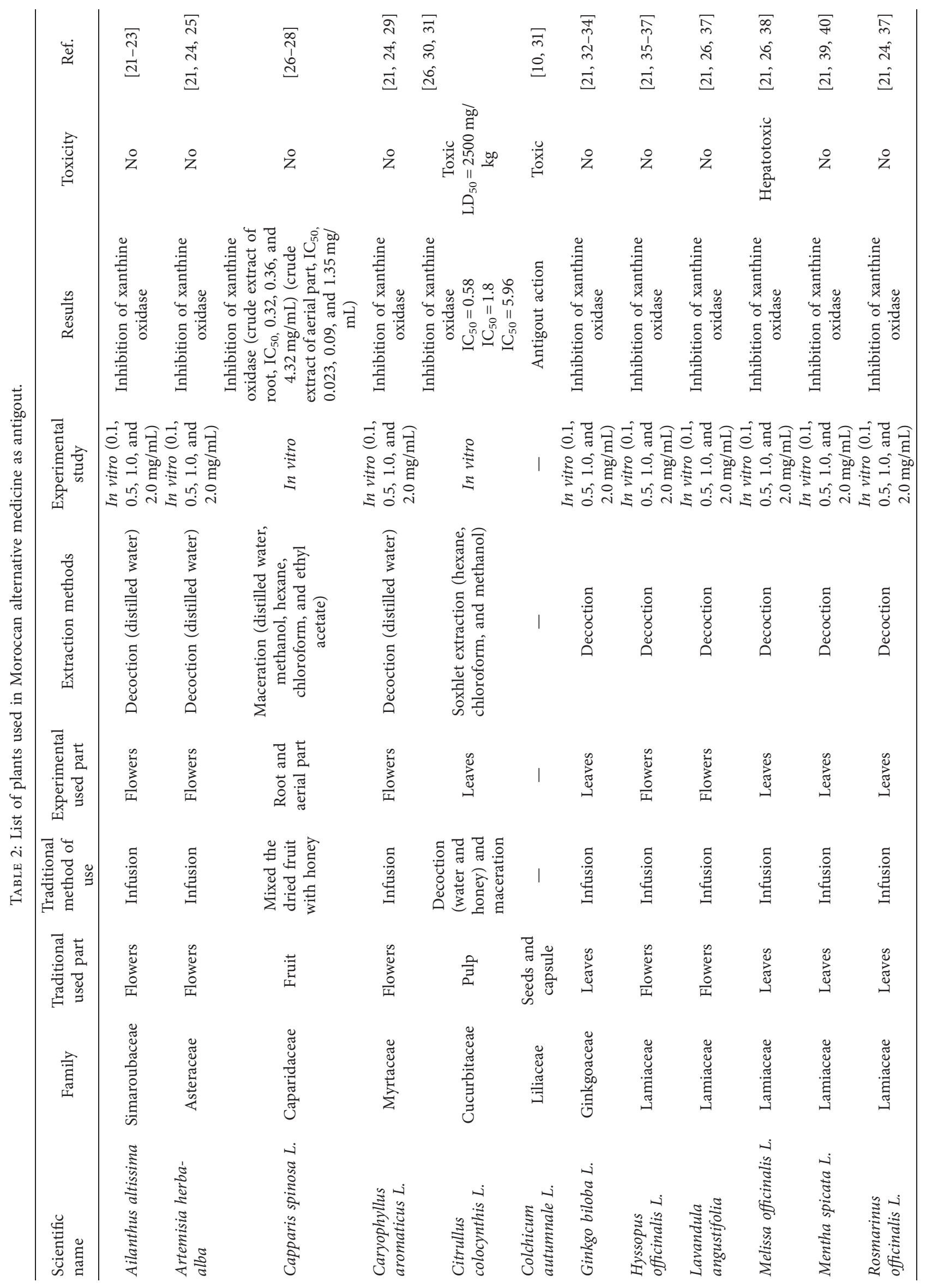




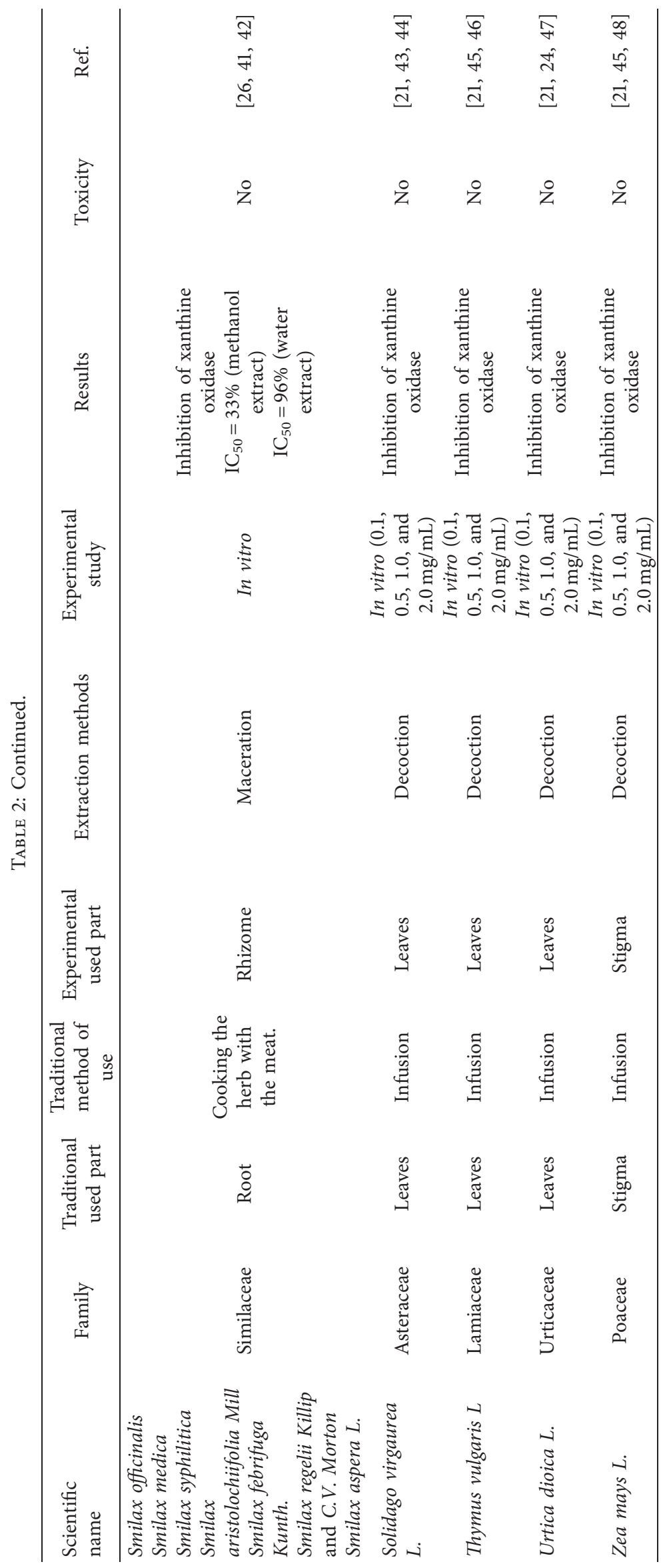




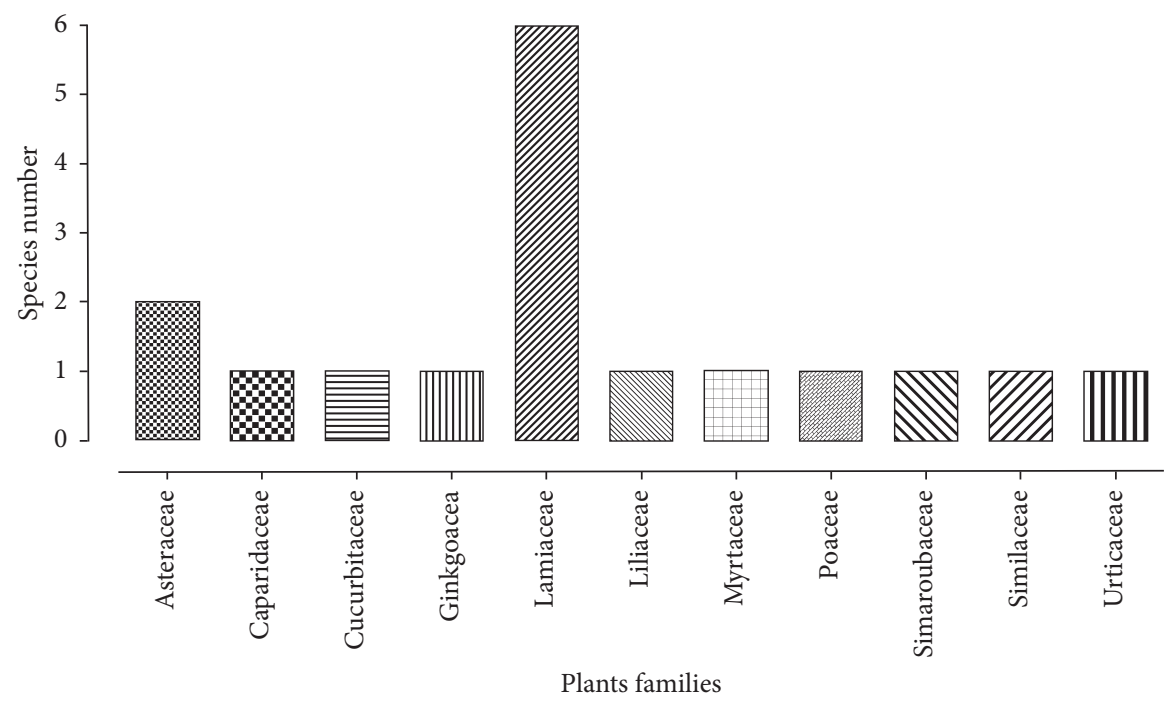

FIgURE 2: Repartition of the different antigout plant families.

Patients that had both gout and diabetes mellitus are more probable to have a higher mean of triglycerides, highdensity lipoprotein cholesterol, renal dysfunction, lower hemoglobin, and peripheral-neuropathy. Besides, it was reported that these patients are more likely to be heavy, older, and men [77].

\section{Conclusions}

The present work showed that gout is treated with different methods used to block and inhibit uric acid secretion. The first strategy adopted by Moroccan people is based on medication uses which are associated with several adverse effects. However, the second method is more safe as it focused on the utilization of plants and their constituents that take an important place in Moroccan phytotherapy. In fact, this review classifies 23 species that have used traditionally in Morocco to treat gout and have shown experimentally significant xanthine oxidase inhibition: Ailanthus altissima, Artemisia herba-alba, Capparis spinosa L., Caryophyllus aromaticus L., Citrullus colocynthis L., Colchicum autumnale L., Ginkgo biloba L., Hyssopus officinalis L., Lavandula angustifolia, Melissa officinalis L., Mentha spicata L., Rosmarinus officinalis L., Smilax officinalis., Smilax medica Schltdl. and Cham., Smilax syphilitica, Smilax aristolochiifolia Mill., Smilax febrifuga Kunth., Smilax regelii Killip and C.V. Morton, Smilax aspera L., Solidago virgaurea L., Thymus vulgaris L., Urtica dioica L., and Zea mays L. However, several studies are needed to valorize these plants in order to use them to manage and maintain gout disease.

\section{Data Availability}

No data were used to support this study.

\section{Conflicts of Interest}

The authors declare that there are no conflicts of interest.

\section{References}

[1] S. C. W. Tang, "Gout: a disease of kings," Contributions to Nephrology, vol. 192, pp. 77-81, 2018.

[2] R. Angalla, A. Mounir, S. Driouich, F. Z. Abourazzak, and T. Harzy, "Chronic tophaceous gout," The Journal of Rheumatolog, vol. 109, no. 10, pp. 681-682, 2016.

[3] E. K. Li, "Gout: a review of its aetiology and treatment," Hong Kong Medical Journal=Xianggang Yi Xue Za Zhi, vol. 10, no. 4, pp. 261-270, 2004.

[4] E. Roddy and M. Doherty, "Epidemiology of gout," Arthritis Research \& Therapy, vol. 12, no. 6, p. 223, 2010.

[5] E. Krishnan, K. Svendsen, J. D. Neaton, G. Grandits, and L. H. Kuller, "Long-term cardiovascular mortality among middle-aged men with gout," Archives of Internal Medicine, vol. 168, no. 10, pp. 1104-1110, 2008.

[6] H. K. Choi, K. Atkinson, E. W. Karlson, and G. Curhan, "Obesity, weight change, hypertension, diuretic use, and risk of gout in men," Archives of Internal Medicine, vol. 165, no. 7, p. $742,2005$.

[7] S. M. Grundy, H. B. Brewer, J. I. Cleeman, S. C. Smith, and C. Lenfant, "Definition of metabolic syndrome," Circulation, vol. 109, no. 3, pp. 433-438, 2004.

[8] H.-y. Su, C. Yang, D. Liang, and H.-F. Liu, "Research advances in the mechanisms of hyperuricemia-induced renal injury," BioMed Research International, vol. 2020, Article ID 5817348, 12 pages, 2020.

[9] B. Engel, J. Just, M. Bleckwenn, and K Weckbecker, "Treatment options for gout," Deutsches Arzteblatt International, vol. 114, no. 13, pp. 215-222, 2017.

[10] M. E. Fernández-Cuadros, G. Goizueta-San-Martin, B. Varasde-Dios et al., "Colchicine-induced rhabdomyolysis: clinical, biochemical, and neurophysiological features and Review of the Literature," Clinical Medicine Insights: Arthritis and Musculoskeletal Disorders, vol. 12, 2019.

[11] Y. Wang, J. X. Zhu, L. D. Kong, C. Yang, C. H. K. Cheng, and $\mathrm{X}$. Zhang, "Administration of procyanidins from grape seeds reduces serum uric acid levels and decreases hepatic xanthine dehydrogenase/oxidase activities in oxonate-treated mice," Basic \& Clinical Pharmacology \& Toxicology, vol. 94, no. 5, pp. 232-237, 2004. 
[12] M. Eddouks, M. Ajebli, and M. Hebi, "Ethnopharmacological survey of medicinal plants used in Daraa-Tafilalet region (province of Errachidia), Morocco," Journal of Ethnopharmacology, vol. 198, pp. 516-530, 2017.

[13] M. Hmammouchi, Les Plantes Médicinales et Aromatiques Marocaines, de Fedala, Rabat, Morocco, 1999.

[14] R. Buchbinder, J. H. Y. Moi, M. K. Sriranganathan, and C. J. Edwards, "Lifestyle interventions for chronic gout," Cochrane Database of Systematic Reviews, vol. 5, 2013.

[15] W. Silverman, S. Locovei, and G. Dahl, "Probenecid, a gout remedy, inhibits pannexin 1 channels," American Journal of Physiology-Cell Physiology, vol. 295, no. 3, pp. C761-C767, 2008.

[16] P. Kaufmann, M. Török, A. Hänni, P. Roberts, R. Gasser, and S. Krähenbühl, "Mechanisms of benzarone and benzbromarone-induced hepatic toxicity," Hepatology, vol. 41, no. 4, pp. 925-935, 2005.

[17] K. G. Saag, D. Fitz-Patrick, J. Kopicko et al., "Lesinurad combined with allopurinol: a randomized, double blind, placebo controlled study in gout patients with an inadequate response to standard-of-care allopurinol (a US-based study)," Arthritis \& Rheumatology, vol. 69, no. 1, pp. 203-212, 2017.

[18] M.-H. H. Lee, G. G. Graham, K. M. Williams, and R. O. Day, "A benefit-risk assessment of benzbromarone in the treatment of gout," Drug Safety, vol. 31, no. 8, pp. 643-665, 2008.

[19] J. D. Herrington and B. C. Dinh, "Fixed, low-dose rasburicase for the treatment or prevention of hyperuricemia in adult oncology patients," Journal of Oncology Pharmacy Practice, vol. 21, no. 2, pp. 111-117, 2015.

[20] N. Dubchak and G. F. Falasca, "New and improved strategies for the treatment of gout," International Journal of Nephrology and Renovascular Disease, vol. 20, no. 3, pp. 145-166, 2010.

[21] L. El Harrad and A. Amine, "Amperometric biosensor based on prussian blue and nafion modified screen-printed electrode for screening of potential xanthine oxidase inhibitors from medicinal plants," Enzyme and Microbial Technology, vol. 85, pp. 57-63, 2016.

[22] B. Balkan, S. Balkan, H. Aydoğdu, and O. Özcan, "Antifungal activities of Ailanthus altissima swingle and juglans regia L. Leaves against some cereal fungi," Journal of Applied Biological Sciences, vol. 8, no. 1, pp. 76-79, 2014.

[23] C. Bourke, "Lack of toxicity of Ailanthus altissima (tree-ofheaven) for goats." Australian Veterinary Journal, vol. 74, no. 6, p. 465, 1996.

[24] A. Ziyyat, A. Legssyer, H. Mekhfi, A. Dassouli, M. Serhrouchni, and W. Benjelloun, "Phytotherapy of hypertension and diabetes in oriental Morocco," Journal of Ethnopharmacology, vol. 58, no. 1, pp. 45-54, 1997.

[25] S. M. Al-Khazraji, L. A. Al-Shamaony, and H. A. A. Twaij, "Hypoglycaemic effect of Artemisia herba alba. I. Effect of different parts and influence of the solvent on hypoglycaemic activity," Journal of Ethnopharmacology, vol. 40, no. 3, pp. 163-166, 1993.

[26] J. Belakhdar, Contribution à l'étude de la Pharmacopée Traditionnelle au Maroc: La Situation Actuelle, les Produits, les Sources du Savoir Enquête Ethnopharmacologique de Terrain Réalisée de 1969 ù 1992, Metz, Paris, France, 1997.

[27] A. Baghiani, D. Ameni, S. Boumerfeg et al., "Studies of antioxidants and xanthine oxidase inhibitory potentials of root and aerial parts of medicinal plant Capparis spinosa L." American Journal of Medicine and Medical Sciences, vol. 2, no. 1, pp. 25-32, 2012.

[28] A. Mollica, G. Zengin, M. Locatelli et al., "Anti-diabetic and anti-hyperlipidemic properties of Capparis spinosa L.: in vivo and in vitro evaluation of its nutraceutical potential," Journal of Functional Foods, vol. 35, pp. 32-42, 2017.

[29] M. A. R. Chowdhury, Manirujjama, M. Basak, M. H. Rahman, and S. Sultana, "Qualitative and quantitative screening of Syzygium aromaticum (Myrtaceae) and evaluation of antihyperglycemic effect," International Journal of Pharmacognosy and Phytochemical Research, vol. 8, no. 7, pp. 1209-1217, 2016.

[30] F. Nessa, A. Khan, and S. Khan, "Evaluation of antioxidant and xanthine oxidase inhibitory activity of different solvent extracts of leaves of Citrullus colocynthis," Pharmacognosy Research, vol. 6, no. 3, p. 218, 2014.

[31] M. Bnouham, F. Z. Merhfour, and M. Elachoui, "Toxic effects of some medicinal plants used in Moroccan traditional medicine," Moroccan Journal of Biology, vol. 3, pp. 21-30, 2006.

[32] M. Bnouham, A. Ziyyat, H. Mekhfi, A. Tahri, and A. Legssyer, "Medicinal plants with potential antidiabetic activity-a review of ten years of herbal medicine research (1990-2000)," International Journal of Diabetes and Metabolism, vol. 14, no. 1, pp. 1-25, 2006.

[33] D. Hammadi, M. Ahmed, K. W. Boudjethia, A. Boukhalfa, and N. Djebli, "Ethnomedicinal survey of medicinal plants used in the western region of Algeria," Medicinal \& Aromatic Plants, vol. 5, no. 1, 2016.

[34] S. R. Naik and V. S. Panda, "Antioxidant and hepatoprotective effects of Ginkgo biloba phytosomes in carbon tetrachlorideinduced liver injury in rodents," Liver International, vol. 27, no. 3, pp. 393-399, 2007.

[35] F. Fathiazad and S. Hamedeyazdan, "A review on Hyssopus officinalis L.: composition and biological activities," African Journal of Microbiology Research, vol. 5, no. 17, pp. 1959-1966, 2011.

[36] K. N. Singh, “Traditional knowledge on ethnobotanical uses of plant biodiversity: a detailed study from the Indian western Himalaya," Biodiversity: Research and Conservation, vol. 28, no. 1, pp. 63-77, 2012.

[37] A. Anadón, M. R. Martínez-larrañaga, M. A. Martínez et al., "Acute oral safety study of rosemary extracts in rats," Journal of Food Protection, vol. 71, no. 4, pp. 790-795, 2008.

[38] A. Namjoo, M. Mirvakili, H. Shirzad, and M. Faghani, "Biochemical, liver and renal toxicities of Melissa officinals hydroalcoholic extract on balb/C mice," Journal of HerbMed Pharmacology, vol. 2, no. 2, pp. 35-40, 2013.

[39] M. Ojewumi, S. Adedokun, O. Omodara, E. Oyeniyi, O. Taiwo, and E. Ojewumi, "Phytochemical and antimicrobial activities of the leaf oil extract of Mentha spicata and its efficacy in repelling mosquito," International Journal of Pharmaceutical Research \& Allied Sciences, vol. 6, no. 4, pp. 17-27, 2017.

[40] J. Naidu, R. Ismail, and S. Sasidharan, "Acute oral toxicity and brine shrimp lethality of methanol extract of Mentha Spicata L (Lamiaceae)," Tropical Journal of Pharmaceutical Research, vol. 13, no. 1, pp. 101-107, 2014.

[41] L. D. Kong, Y. Cai, W. W. Huang, C. H. K. Cheng, and R. X. Tan, "Inhibition of xanthine oxidase by some Chinese medicinal plants used to treat gout," Journal of Ethnopharmacology, vol. 73, no. 1-2, pp. 199-207, 2000.

[42] Z. Intan Suziana, N. Z. Nik Aina Syazana, A. Afzanizan, S. Y. Lau, R. Nurul Syahida, and M. S. Dasuki, "Evaluation of toxicity in Smilax myosotiflora plant," International Medical Journal, vol. 23, no. 6, pp. 696-699, 2016. 
[43] B. Thiem and O. Golińska, "Antimicrobial activity of Solidago virgaurea L. from in vitro cultures," Fitoterapia, vol. 73, no. 6 , pp. 514-516, 2002.

[44] A. Bucciarelli, A. Minetti, C. Milczakowskyg, and M. Skliar, "Evaluation of gastroprotective activity and acute toxicity ofSolidago chilensisMeyen (Asteraceae)," Pharmaceutical Biology, vol. 48, no. 9, pp. 1025-1030, 2010.

[45] F. Jamila and E. Mostafa, "Ethnobotanical survey of medicinal plants used by people in Oriental Morocco to manage various ailments," Journal of Ethnopharmacology, vol. 154, no. 1, pp. 76-87, 2014.

[46] F. Benourad, Z. Kahvecioglu, M. Youcef-Benkada, and J.-M. Colet, "Prospective evaluation of potential toxicity of repeated doses of Thymus vulgarisL. extracts in rats by means of clinical chemistry, histopathology and NMR-based metabonomic approach," Drug Testing and Analysis, vol. 6, no. 10, pp. 1069-1075, 2014.

[47] S. A. Dar, F. A. Ganai, A. R. Yousuf, M. Balkhi, T. M. Bhat, and P. Sharma, "Pharmacological and toxicological evaluation ofUrtica dioica," Pharmaceutical Biology, vol. 51, no. 2, pp. 170-180, 2013.

[48] A. W. Ha, H. J. Kang, S. L. Kim, M. H. Kim, and W. K. Kim, "Acute and subacute toxicity evaluation of corn silk extract," Preventive Nutrition and Food Science, vol. 23, no. 1, pp. 70-76, 2018.

[49] M. D. Brigham, L. P. Radeck, C. M. Mendonca et al., "Gout severity in recipients of kidney transplant," Transplantation Proceedings, vol. 51, no. 6, pp. 1816-1821, 2019.

[50] L. J. Moilanen, M. Hämäläinen, L. Lehtimäki, R. M. Nieminen, and E. Moilanen, "Urate crystal induced inflammation and joint pain are reduced in transient receptor potential ankyrin 1 deficient mice - potential role for transient receptor potential ankyrin 1 in gout," PLoS One, vol. 10, no. 2, pp. 1-13, 2015.

[51] C. A. Dinarello, "A clinical perspective of $\mathrm{IL}-1 \beta$ as the gatekeeper of inflammation," European Journal of Immunology, vol. 41, no. 5, pp. 1203-1217, 2011.

[52] D. Singh and K. K. Huston, "IL-1 inhibition with anakinra in a patient with refractory gout," JCR: Journal of Clinical Rheumatology, vol. 15, no. 7, p. 366, 2009.

[53] A. So, M. De Meulemeester, A. Pikhlak et al., "Canakinumab for the treatment of acute flares in difficult-to-treat gouty arthritis: results of a multicenter, phase II, dose-ranging study," Arthritis \& Rheumatism, vol. 62, no. 10, pp. 3064-3076, 2010.

[54] R. A. Terkeltaub, H. R. Schumacher, and J. D. Carter, "Rilonacept in the treatment of acute gouty arthritis: a randomized, controlled clinical trial using indomethacin as the active comparator," Arthritis Research and Therapy, vol. 15, no. 1, pp. 1-10, 2013.

[55] B. Howley and H. O. Fearnhead, "Caspases as therapeutic targets," Journal of Cellular and Molecular Medicine, vol. 12, no. 5, pp. 1502-1516, 2008.

[56] G. Howatson, M. P. McHugh, J. A. Hill et al., "Influence of tart cherry juice on indices of recovery following marathon running," Scandinavian Journal of Medicine \& Science in Sports, vol. 20, no. 6, pp. 843-852, 2010.

[57] X. Gao, G. Curhan, J. Forman, A. Ascherio, and H. K Choi, "Vitamin C intake and serum uric acid concentration in men," The Journal of Rheumatology, vol. 35, no. 9, pp. 1853-1858, 2008.

[58] M. A. Martillo, L. Nazzal, and D. B. Crittenden, "The crystallization of monosodium urate," Current Rheumatology Reports, vol. 16, no. 2, p. 400, 2014.
[59] D.-H. Tang, Y.-S. Ye, C.-Y. Wang, Z.-L. Li, H. Zheng, and K.-L. Ma, "Potassium oxonate induces acute hyperuricemia in the tree shrew (tupaia belangeri chinensis)," Experimental Animals, vol. 66, no. 3, pp. 209-216, 2017.

[60] Q. Su, H. Su, Z. Nong et al., "Hypouricemic and nephroprotective effects of an active fraction from," $K B R$, vol. 43, no. 1, pp. 220-233, 2018.

[61] M. T. Mansouri, A. A. Hemmati, B. Naghizadeh, S. A. Mard, A. Rezaie, and B. Ghorbanzadeh, "A study of the mechanisms underlying the anti-inflammatory effect of ellagic acid in carrageenan-induced paw edema in rats,," Indian Journal of Pharmacology, vol. 47, no. 3, pp. 292-298, 2015.

[62] M. T. Nguyen, S. Awale, Y. Tezuka, Q. Le Tran, H. Watanabe, and S. Kadota, "Xanthine oxidase inhibitory activity of Vietnamese medicinal plants," Biological and Pharmaceutical Bulletin, vol. 27, no. 9, pp. 1414-1421, 2004.

[63] A. Pisano, V. Cernaro, G. Gembillo, G. D’Arrigo, M. Buemi, and D. Bolignano, "Xanthine oxidase inhibitors for improving renal function in chronic kidney disease patients: an updated systematic review and meta-analysis," International Journal of Molecular Sciences, vol. 18, no. 11, 2017.

[64] A. Mehmood, M. Ishaq, L. Zhao et al., "Natural compounds with xanthine oxidase inhibitory activity: a review," Chemical Biology \& Drug Design, vol. 93, no. 4, pp. 387-418, 2019.

[65] P. W. Peake, B. A. Pussell, P. Martyn, V. Timmermans, and J. A. Charlesworth, "The Inhibitory effect of rosmarinic acid on Complement involves the C5 convertase," International Journal of Immunopharmacology, vol. 13, no. 7, pp. 853-857, 1991.

[66] Y. I. Kwon, D. A. Vattem, and K. Shetty, "Evaluation of clonal herbs of Lamiaceae species for management of diabetes and hypertension," Asia Pacific Journal of Clinical Nutrition, vol. 15, no. 1, pp. 107-118, 2006.

[67] A. G. González, I. L. Bazzocchi, L. Moujir, A. G. Ravelo, M. D. Correa, and M. P. Gupta, "Xanthine oxidase inhibitory activity of some Panamanian plants from Celastraceae and Lamiaceae," Journal of Ethnopharmacology, vol. 46, no. 1, pp. 25-29, 1995.

[68] H. Vahid, H. Rakhshandeh, and A. Ghorbani, "Antidiabetic properties of Capparis spinosa L. and its components," Biomedicine and Pharmacotherapy, vol. 92, pp. 293-302, 2017.

[69] S. F. Nabavi, F. Maggi, M. Daglia, S. Habtemariam, L. Rastrelli, and S. M. Nabavi, "Pharmacological effects of Capparis spinosa L.” Phytotherapy Research, vol. 30, no. 11, pp. 1733-1744, 2016.

[70] S. K. Oudah, R. M. Al-Salih, and S. H. Gusar, "Study the role of polyphenolic extract of Capparis spinosa L. leaves as a hypoglycemic agent," Journal of Scientific \& Engineering Research, vol. 5, no. 5, pp. 1561-1575, 2004.

[71] A. K. N. Tlili, A. Feriani, E. Saadoui, and N. Nasri, "Capparis spinosa leaves extract: source of bioantioxidants with nephroprotective and hepatoprotective effects," Biomedicine \& Pharmacotherapy, vol. 87, pp. 171-179, 2017.

[72] M. H. S. N. Mohebali, S. A. Shahzadeh Fazeli, H. Ghafoori et al., "Effect of flavonoids rich extract of Capparis spinosa on inflammatory involved genes in amyloid-beta peptide injected rat model of Alzheimer's disease," Nutritional Neuroscience, vol. 21, no. 2, pp. 143-150, 2016.

[73] H. Zhang and Z. F. Ma, "Phytochemical and pharmacological properties of capparis spinosa as a medicinal plant," Nutrients, vol. 10, no. 2, pp. 1-14, 2018.

[74] B. D. Prendergast and C. F. George, "Drug-induced rhabdomyolysis - mechanisms and management," Postgraduate Medical Journal, vol. 69, no. 811, pp. 333-336, 1993. 
[75] K. Wilbur and M. Makowsky, "Colchicine myotoxicity: case reports and literature review," Pharmacotherapy, vol. 24, no. 12, pp. 1784-1792, 2004.

[76] Y. Finkelstein, S. E. Aks, and J. R. Hutson, "Colchicine poisoning: the dark side of an ancient drug," Clinical Toxicology, vol. 48, no. 5, pp. 407-414, 2010.

[77] A. Collier, A. Stirling, L. Cameron, M. Hair, and D. Crosbie, "Gout and diabetes: a common combination," Postgraduate Medical Journal, vol. 92, no. 1089, pp. 372-378, 2016.

[78] H. K. Choi, M. A. De Vera, and E. Krishnan, "Gout and the risk of type 2 diabetes among men with a high cardiovascular risk profile," Rheumatology, vol. 47, no. 10, pp. 1567-1570, 2008.

[79] H. Ito, M. Abe, and M. Mifune, "Hyperuricemia is independently associated with coronary heart disease and renal dysfunction in patients with type 2 diabetes mellitus," PLoS One, vol. 6, no. 11, 2011. 